\title{
Resource allocations when projects have ranges of increasing returns
}

\section{Catherine Bobtcheff • Christian Gollier • Richard Zeckhauser}

Published online: 29 July 2008

(C) Springer Science + Business Media, LLC 2008

\section{Publisher's Erratum to: J Risk Uncertain DOI 10.1007/s11166-008-9044-y}

In the original article Fig. 5 was mistakenly substituted for Fig. 4. The correct Fig. 4 is shown below. The publisher regrets the error.

expected benefits

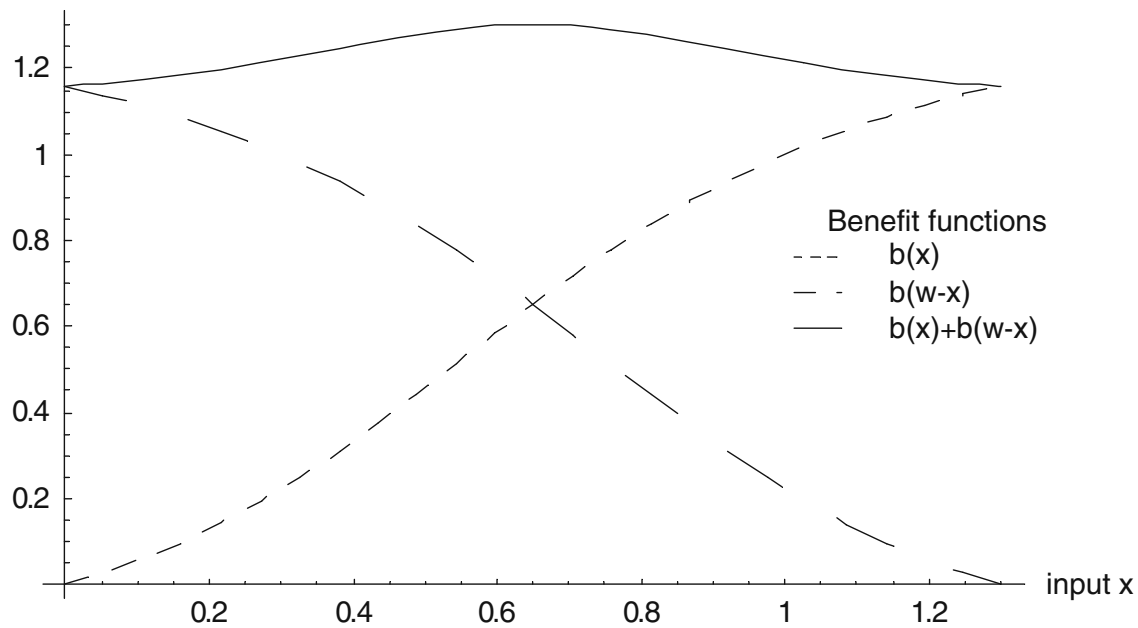

Fig. 4 The two expected benefit functions together with the objective function for a high value of $w$

The online version of the original article can be found at http://dx.doi.org/10.1007/s11166-008-9044-y.

C. Bobtcheff $(\bowtie)$

Toulouse School of Economics (LERNA and CNRS), 21 allée de Brienne, 31000 Toulouse, France e-mail: catherine.bobtcheff@univ-tlse1.fr

C. Gollier

Toulouse School of Economics (LERNA and IDEI), 21 allée de Brienne, 31000 Toulouse, France

R. Zeckhauser

Harvard University, Cambridge, MA, USA 